\title{
GAMBARAN HISTOLOGIK HATI TIKUS WISTAR YANG DIBERI VIRGIN COCONUT OIL DENGAN INDUKSI PARASETAMOL
}

\author{
${ }^{1}$ Amelia F. Manatar \\ ${ }^{2}$ Sunny Wangko \\ ${ }^{2}$ Marie M. Kaseke
}

\author{
${ }^{1}$ Kandidat Skripsi Fakultas Kedokteran Universitas Sam Ratulangi Manado \\ ${ }^{2}$ Bagian Anatomi-Histologi Fakultas Kedokteran Universitas Sam Ratulangi Mando \\ Email: ameliamanatar09347@yahoo.com
}

\begin{abstract}
Virgin Coconut Oil (VCO) is defined as a multifunction supplement of health. Previous research has proved that it can be used for anti-inflammation, anti-pyretic, antioxidant, and for metabolism repairments. This VCO will be biotransformed in the liver. Paracetamol is an analgetic and antipyretic medicine which is usually used for selfmedication. Over dosage of paracetamol is potentially destructive for the liver, which is the major detoxification organ. This study aimed to find out the histological changes of wistar livers treated with VCO after being induced with paracetamol. This was an experimental study using the post-test-only control group design. This study was conducted for 12 days. As subjects, we used 22 male wistars divided into five groups: negative control group (KN); positive control group (KP) treated with toxic dosages of paracetamol $(2.5 \mathrm{~g} / \mathrm{kg} \mathrm{BW} /$ day $)$ from day 8 to 12; and three treatment groups (P1, P2, and P3) given VCO $1 \mathrm{ml}, 5 \mathrm{ml}$, and 10 $\mathrm{ml}$ per $\mathrm{kg} \mathrm{BW} /$ day consecutively for 12 days, added with the paracetamol $2.5 \mathrm{~g} / \mathrm{kg} \mathrm{BW} /$ day from day 8 to 12 . Some wistars from each group were terminated on day 10 and the others on day 13. Their livers were examined for macroscopic and microscopic observations. The histological changes found were: lipid degeneration, hydrophic degeneration, and necrosis of hepatocytes in the KP, P1, P2, and P3. The P2 showed less liver destruction than KP, P1, and P3. Moreover, hepatocyte regeneration was found in P1 and P2. Conclusion: Paracetamol induction of toxic dosages $2.5 \mathrm{~g} / \mathrm{kg} \mathrm{BW}$ resulted in histological changes of the wistar livers (hydrophic degeneration, fatty degeneration, and hepatocyte necrosis). Treatment with VCO 1 $\mathrm{ml}$ and $5 \mathrm{ml} / \mathrm{kg} \mathrm{BW} / \mathrm{day}$ could diminish the changes and stimulate the regeneration of hepatocytes. However, with a maximal dosage of $10 \mathrm{ml} / \mathrm{kg}$ BW/day, VCO worsened the injured liver marked by diffuse fatty degeneration of the livers.
\end{abstract}

Keywords: liver destruction, paracetamol, virgin coconut oil.

Abstrak: Virgin Coconut Oil (VCO) diyakini memiliki banyak fungsi yang berkaitan dengan
kesehatan. VCO berkhasiat sebagai anti inflamasi, anti piretik, antioksidan, dan memperbaiki
fungsi metabolisme tubuh. Parasetamol merupakan obat analgetik dan antipiretik yang banyak
digunakan. Toksisitas akut dari obat ini berpotensi menimbulkan kerusakan hati. Penelitian ini
bertujuan untuk melihat gambaran histologik hati tikus wistar yang diberi VCO disertai
induksi parasetamol. Penelitian ini bersifat eksperimental dengan rancangan penelitian the
post test only control group design. Subyek penelitian yaitu dua puluh dua ekor wistar jantan
dibagi dalam lima kelompok, yaitu: kontrol negatif (KN), kontrol positif (KP) yang diberi
parasetamol dosis toksik $2,5 \mathrm{~g} / \mathrm{kg} \mathrm{BB} / \mathrm{hari}$ pada hari ke $8-12$, dan kelompok perlakuan 1 , 2 ,
dan 3 (P1, P2, dan P3) yang diberi VCO masing-masing kelompok perlakuan 1 ml, 5 ml. dan
$10 \mathrm{ml}$ per kg BB/hari selama 12 hari dengan pemberian parasetamol $2,5 \mathrm{~g} / \mathrm{kg} \mathrm{BB} /$ hari dimulai
pada hari ke $8-12$. Hasil penelitian menunjukkan perubahan gambaran struktur histologik hati
berupa degenerasi lemak, degenerasi hidropik, dan nekrosis pada kelompok KP, P1, P2, dan
P3. Kelompok P2 memperlihatkan lebih sedikit perubahan histologik hati dibandingkan 
kelompok KP, P1 dan P3. Aktivitas regenerasi hepatosit ditemukan pada kelompok P1 dan P2. Simpulan: Induksi parasetamol dosis toksik $2,5 \mathrm{~g} / \mathrm{kg}$ BB mengakibatkan perubahan histologik hati berupa degenerasi hidropik, degenerasi lemak, dan nekrosis hepatosit. Pemberian VCO dosis $1 \mathrm{ml} / \mathrm{kg}$ BB dan $5 \mathrm{ml} / \mathrm{kg}$ BB dapat mengurangi terjadinya perubahan tersebut serta mampu merangsang regenerasi hepatosit secara cepat sedangkan pemberian VCO dosis maksimal $10 \mathrm{ml} / \mathrm{kg} \mathrm{BB}$ memperparah cedera hati dengan terjadinya degenerasi lemak yang difus.

Kata kunci: kerusakan hati, parasetamol, virgin coconut oil.

Dewasa ini, manfaat kesehatan dan gizi minyak kelapa sangat berperan dalam kesehatan sebagai bahan fungsional yang penting. ${ }^{1}$ Minyak kelapa murni atau yang disebut dengan Virgin Coconut Oil (VCO) adalah minyak yang dihasilkan dari buah kelapa(Cocos nucifera) segar tanpa melalui penambahan bahan kimia atau proses yang menggunakan panas tinggi. ${ }^{2}$ Tanaman kelapa yang mampu menghasilkan VCO tersebut merupakan komoditas perkebunan yang banyak dihasilkan di Sulawesi Utara sebagai daerah penghasil kelapa yang utama di Indonesia, dengan luas area perkebunan mencakup 271.277 ha dan jumlah produksi mencapai 292.850 ton pada tahun 2003. ${ }^{3}$ Dibandingkan dengan minyak nabati lainnya seperti minyak sawit, minyak kedelai, minyak jagung, dan minyak bunga matahari, VCO memiliki beberapa keunggulan, antara lain kandungan asam laurat $\left(\mathrm{C}_{11} \mathrm{H}_{23} \mathrm{COOH}\right)$ dan komposisi asam lemak rantai menengah (medium chain fatty acid/MCFA) yang tinggi serta berat molekul yang rendah. ${ }^{4}$

Penelitian lanjut saat ini membuktikan bahwa VCO memiliki beberapa efek farmakologik seperti anti-inflamasi, antipiretik, dan analgetik. ${ }^{4,5}$ Selain itu, beberapa penelitian mengemukakan bahwa VCO bermanfaat untuk menurunkan kadar kolesterol darah total, mempercepat waktu penyembuhan luka, serta berpotensi sebagai antioksidan. ${ }^{6-9}$ Penelitian Nevin dan Rajamohan. ${ }^{7,8}$ mengidentifikasi efek antioksidan VCO terhadap tikus dalam menurunkan kadar lipid dan peroksidasi lipid oleh karena tingginya komponen aktivitas biologik VCO seperti fitosterol, vitamin E, dan polifenol. Zakaria et al. ${ }^{10} \mathrm{di}$ Malaysia telah membuktikan bahwa VCO dapat berefek hepatoprotektif.

Hati merupakan organ yang berperan dalam pusat metabolisme berbagai zat/ bahan yang masuk kedalam tubuh. ${ }^{10}$ Salah satu fungsi hati yang penting bagi tubuh ialah melindungi penumpukan zat berbahaya dan beracun yang masuk dari luar tubuh (xenobiotic substances), antara lain obat-obatan. Parasetamol merupakan salah satu obat yang dapat berefek hepatotoksik. Penggunaan parasetamol sebagai analgetik dan antipiretik telah dikenal oleh masyarakat umum dan banyak dijual bebas di pasaran. Hal ini menyebabkan masyarakat dapat mengonsumsinya tanpa harus menggunakan resep dokter; selain itu, pengetahuan masyarakat mengenai bahaya toksisitas obat masih sangat kurang, terutama bila digunakan dalam dosis berlebihan. Hampir setengah dari kasus percobaan bunuh diri di USA disebabkan oleh overdosis parasetamol. ${ }^{11,12}$

Penelitian mengenai manfaat VCO sudah sejak lama dan banyak dilakukan tetapi masih kurang yang membahas peran VCO sebagai bahan hepatoprotektif. Selain itu, mengingat daerah Sulawesi Utara berpotensi besar untuk menghasilkan VCO yang berkualitas dalam bidang kesehatan, maka peneliti tertarik untuk meneliti perubahan histologik yang terjadi pada hati akibat paparan bahan yang dapat bersifat toksik, dalam hal ini parasetamol, serta efek pemberian VCO terhadap hati wistar yang diinduksi parasetamol.

\section{METODE PENELITIAN}

Penelitian ini bersifat eksperimental dengan rancangan penelitian sederhana the post test only control group design. 
Penelitian dilakukan di Laboratorium Riset Terpadu dan Pusat Diagnostik Patologi Anatomi mulai akhir bulan Oktober 2012 sampai bulan Desember 2012.

Subjek penelitian terdiri dari 22 ekor tikus wistar dengan kriteria inklusi yaitu usia wistar 4-5 bulan, jenis kelamin jantan, berat badan 150-200 gram, dan secara fisik terlihat sehat, aktif, dan tidak ada bagian tubuh yang luka.

Alat yang digunakan meliputi naso gastric tube (NGT) no.5, semprit 5cc, gunting, sarung tangan, pisau bedah, mikrotom, waterbath, gelas objek, mikroskop, kamera, dan timbangan.

Bahan yang digunakan ialah VCO produk komersil lokal dari Sulawesi Utara, tablet parasetamol $500 \mathrm{mg}$, pelet AD2, akuades, alkohol, xylol, dan hematoksilin eosin (HE).

\section{Prosedur kerja}

Subyek penelitian tikus wistar jantan dibagi atas lima kelompok: kontrol negatif (KN) dua ekor tikus, serta kelompok kontrol positif (KP), perlakuan 1 (P1), perlakuan 2 (P2), dan perlakuan 3 (P3) masing-masing 5 ekor tikus.

Penelitian berlangsung selama 12 hari. Kelompok KN diberikan pelet AD2 dan air PAM. Kelompok KP diberikan parasetamol dengan dosis toksik 2,5 $\mathrm{g} / \mathrm{kgBB}$ selama 4 hari (hari ke-9 s/d ke12). Kelompok perlakuan yaitu: kelompok P1 yang diberikan VCO dosis $1 \mathrm{ml} / \mathrm{kg}$ $\mathrm{BB} /$ hari selama 12 hari (hari ke-1 s/d ke12) serta parasetamol $2,5 \mathrm{~g} / \mathrm{kg} \mathrm{BB} / \mathrm{hari}$ selama 4 hari (hari ke-9 s/d ke-12); kelompok P2 yang diberikan VCO dosis 5 $\mathrm{ml} / \mathrm{kg} \mathrm{BB} /$ hari selama 12 hari (hari ke-1 s/d ke-12), ditambahkan parasetamol 2,5 g/kg BB selama 4 hari (hari ke-9 s/d ke-12); dan kelompok P3 yang diberikan VCO dosis 10 $\mathrm{ml} / \mathrm{kg}$ BB selama 12 hari (hari ke-1 s/d ke12) ditambahkan parasetamol $2,5 \mathrm{~g} / \mathrm{kg} \mathrm{BB}$ selama 4 hari (hari ke- 8 s/d ke-12).

Parasetamol yang digunakan dilarutkan dalam akuades dan diberikan per oral melalui NGT no. 5. Sebagian wistar dari masing-masing kelompok diterminasi pada hari ke-10 dan sisanya setelah semua perlakuan selesai diberikan yaitu pada hari ke-13. Pemrosesan sampel lanjut dilakukan di Pusat Diagnostik Patologi Anatomi Manado.

\section{HASIL PENELITIAN}

Hasil pengamatan makroskopik hati pada kelima kelompok wistar tidak menunjukkan perbedaan yang mencolok. Pada kelompok KP terlihat adanya bercak kekuningan pada permukaan hati yang nampak pucat (Gambar 1B).

Gambaran mikroskopik hati tikus wistar dari masing-masing kelompok memperlihatkan perbedaan yang cukup menonjol. Kelompok KN memperlihatkan gambaran hati normal dengan hepatosit tersusun radier, vena sentralis jelas, inti normokromatis, dan lempeng-lempeng hati beranastomosis secara bebas membatasi sinusoid (Gambar 2A). Kelompok KP memperlihatkan nekrosis sentrilobularis di sekitar vena sentralis (Gambar 2B).
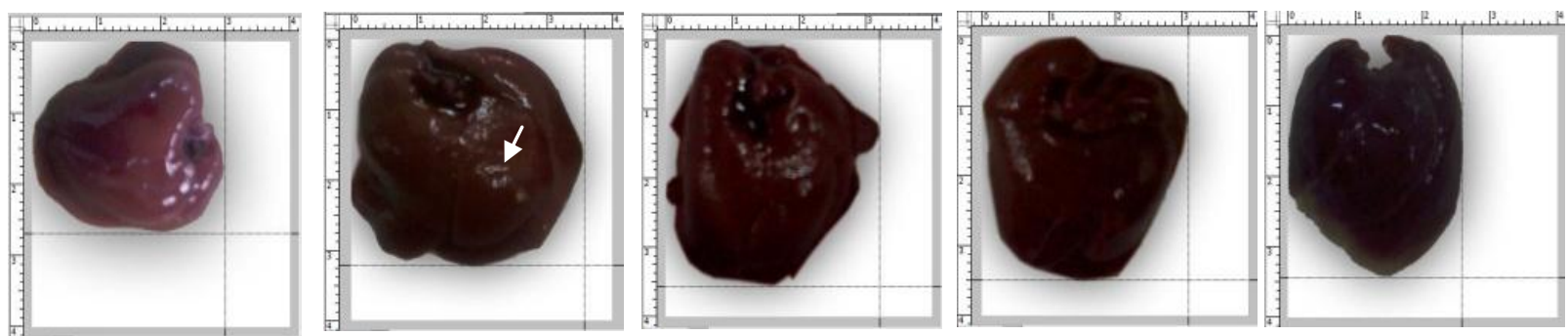

Gambar 1. Makroskopik hati tikus (skala dalam $\mathrm{cm}$ ). A) Kontrol negatif, B) Kontrol positif, C) Perlakuan 1 (P1) D) Perlakuan 2 (P2), dan E) Perlakuan 3 (P3). Anak panah menunjukkan bercak kekuningan pada permukaan hati (KP). 
Kelompok P1 memperlihatkan nekrosis yang cukup luas dengan infiltrasi sel-sel radang berbatasan dengan daerah hati yang normal (Gambar 2C). Kelompok P2 memperlihatkan vena sentralis dan sinusoid yang tampak normal dengan

aktivitas regenerasi sel yang hampir menyeluruh dan mikroarsitektur hati mulai teratur kembali (Gambar 2D). Kelompok P3 memperlihatkan cedera sel yang lebih banyak berupa degenerasi lemak yang difus (Gambar 2E).
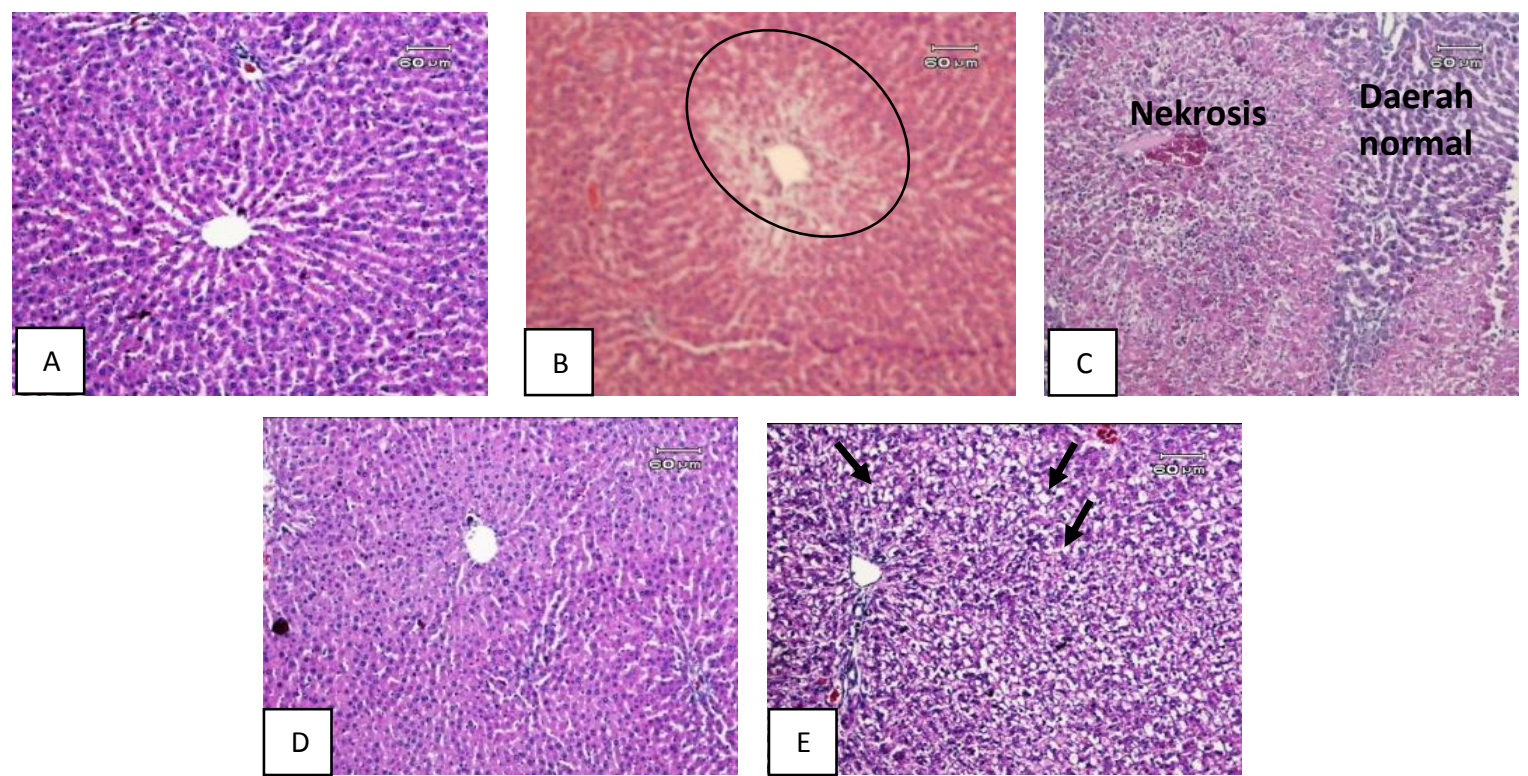

Gambar 2. Mikroskopik hati tikus wistar. A) Kontrol negatif, tampak vena sentralis dan sinusoid, B) Kontrol positif, tampak nekrosis (daerah berbatas lingkaran) di sekitar vena sentralis, C) Kelompok P1, nekrosis yang cukup luas berbatasan dengan daerah hati yang normal, D) Kelompok P2, struktur vena sentralis dan sinusoid tampak normal, E) Kelompok P3, tampak degenerasi lemak (anak panah).
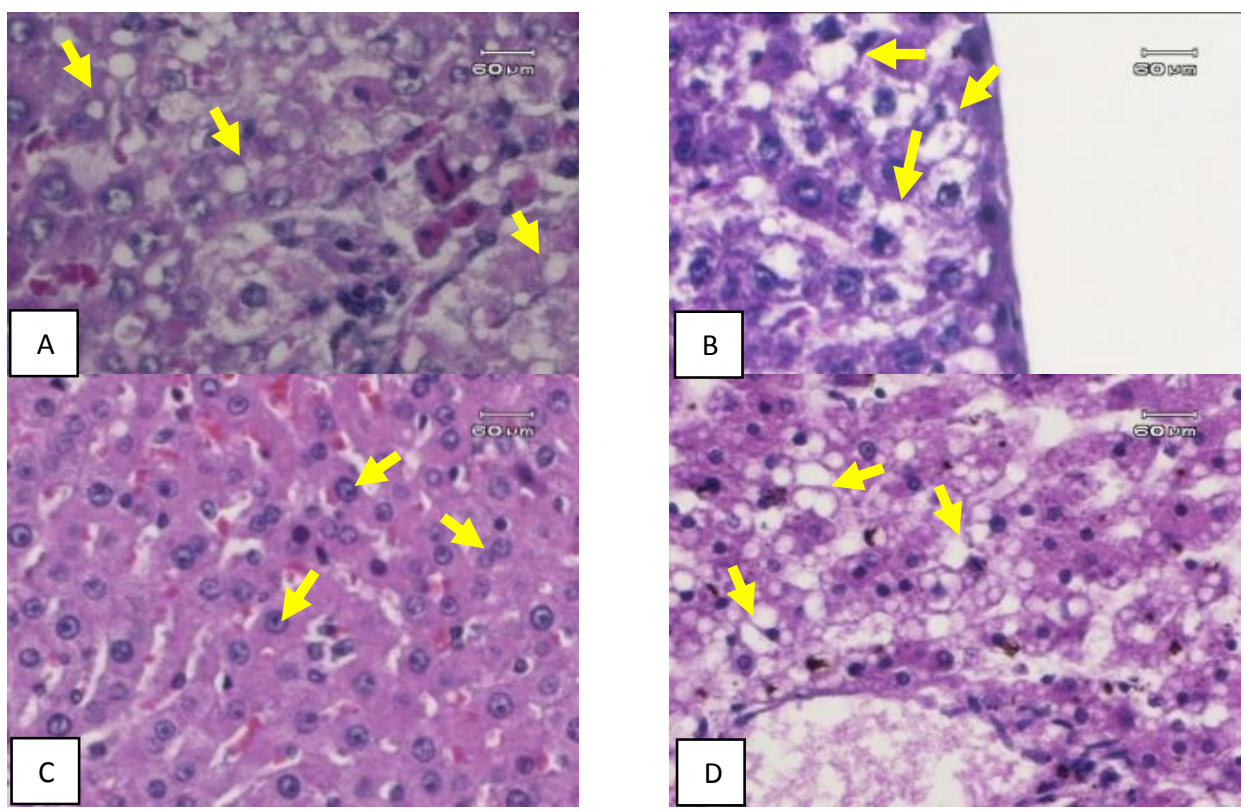

Gambar 3. Mikroskopik hati tikus. A) Kelompok KP, degenerasi hidropik, B) Kelompok P1, degenerasi hidropik pada zona periportal, C) Kelompok P2, regenerasi hepatosit, dan D) Kelompok $\mathrm{P} 3$, degenerasi lemak. 
Gambaran mikroskopik kelompok KP, P1, dan P3 memperlihatkan cedera sel berupa degenerasi hidropik dan degenerasi lemak (Gambar 3A, B, dan E) sedangkan kelompok P2 memperlihatkan regenerasi hepatosit (Gambar 3C). Degenerasi hidropik yang tampak sebagai pembengkakan sel dengan sitoplasma pucat lebih banyak terjadi pada daerah periportal. Pada kelompok P2 tampak aktivitas regenerasi hepatosit sedangkan pada kelompok P3 tampak degenerasi lemak yang difus.

\section{BAHASAN}

Hasil pengamatan makroskopik hati pada kelima kelompok wistar tidak menunjukkan adanya perbedaan yang mencolok. Gambaran makroskopik hati normal juga bisa ditemukan walaupun sudah terjadi perubahan mikroskopik yang belum tampak secara makroskopik. Hal tersebut dapat disebabkan karena waktu penelitian yang singkat sehingga walaupun kerusakan hati sudah terjadi, perubahan struktur hati tingkat makroskopik belum tampak. $^{13}$

Parasetamol dapat mengakibatkan cedera hati yang ditandai oleh peradangan akut pada hepatosit, berupa nekrosis sentrilobularis. ${ }^{14}$ Hasil penelitian ini memperlihatkan bahwa kelompok KP yang mendapatkan parasetamol dosis $2,5 \mathrm{~g} / \mathrm{kg}$ BB mengalami cedera sel berupa degenerasi hidropik, degenerasi lemak sampai nekrosis hepatosit. Kelompok P1 yang diberikan VCO $1 \mathrm{ml} / \mathrm{kg}$ BB disertai induksi parasetamol memperlihatkan adanya degenerasi lemak, degenerasi hidropik dan nekrosis yang cukup luas dibandingkan dengan kelompok P2 yang diberikan VCO $5 \mathrm{ml} / \mathrm{kg}$ BB yang memperlihatkan regenerasi hepatosit secara menyeluruh serta mikroarsitektur hati yang mulai tersusun lebih rapih.

Secara mikroskopik hepatosit memiliki inti bulat, sitoplasma jernih, dan tersusun teratur membentuk lempengan yang radier menuju pusat lobulus (vena sentralis). ${ }^{15}$ Hepatosit yang terpapar parasetamol dosis toksik mengalami cedera melalui serangkaian proses stres oksidatif akibat penumpukan metabolit N-acetyl-pbenzoquinone (NAPQI) yang merusak mitokondria dan menghambat pembentukan energi sel. Nekrosis banyak terjadi di sekitar vena sentralis (nekrosis sentrilobularis) disebabkan karena banyaknya darah yang mengandung zat-zat toksik bermuara ke vena sentralis yang memperparah cedera tersebut; selain itu, keberadaan sitokrom P450 yang banyak terdapat di sekitar vena sentralis yang berperan dalam metabolisme obat-obatan yang masuk ke dalam tubuh. ${ }^{14,15}$

Degenerasi lemak dan degenerasi hidropik merupakan jejas sel reversibel yang terjadi karena peningkatan permeabilitas dinding sel akibat gangguan pompa membran sel ATP-ase dan serangkaian gangguan metabolisme sel akibat toksisitas parasetamol. Degenerasi hidropik ditandai oleh sel yang tampak besar, membengkak, dan sitoplasma yang pucat akibat akumulasi ion natrium di dalam sel. Respon terhadap metabolit toksik parasetamol yang menimbulkan degenerasi lemak ditandai oleh vakuolisasi sitoplasma akibat akumulasi trigliserida. ${ }^{15,16}$

Setiap sel yang mengalami kematian akan digantikan oleh sel-sel baru melalui proses regenerasi, ${ }^{18}$ yang ditandai oleh inti sel yang besar, berinti dua, dan warna kromatin terpulas lebih gelap yang menandakan regenerasi sel yang matur. ${ }^{19}$ Beberapa penelitian terhadap hewan coba tikus dengan paparan bahan toksik memperlihatkan aktivitas regenerasi hepatosit sangat besar, yang bisa mencapai maksimal setelah 5-7 hari. $^{20}$ Dalam penelitian ini, efek proteksi VCO tampak jelas dengan adanya aktivitas regenerasi hepatosit yang hampir menyeluruh pada kelompok P2 (Gambar 3C). Aktivitas regenerasi hepatosit tersebut juga serupa dengan penelitian Mardiyyaningsih et al. ${ }^{17}$ yang mendapatkan penurunan enzim SGPT pada mencit yang diberi diet VCO.

VCO yang tergolong dalam trigliserida rantai sedang (medium chain trygliseride MCT) sangat mudah diserap oleh sel dan mampu meningkatkan metabolisme sel. 
Tambahan energi dari metabolisme tersebut menghasilkan efek stimulasi di dalam sel sehingga sel dapat beregenerasi dan mempunyai daya tahan terhadap radikal bebas. ${ }^{10}$ Sultana et al. ${ }^{21}$ menyatakan bahwa aktivitas hepatoprotektif suatu senyawa obat seringkali juga berkaitan dengan efek senyawa tersebut sebagai agen antioksidan dan scavenger radikal bebas. VCO yang terbukti memiliki aktivitas antioksidan karena berbagai kandungan senyawa aktif seperti fenol dan tokoferol (vitamin E) dapat mengikat radikal bebas dan mencegah pembentukan radikal bebas yang lebih banyak (amplifikasi) sehingga kerusakan hepatosit lebih lanjut dapat dihindari dan sekaligus dapat merangsang regenerasi hepatosit.

Kerusakan sel-sel hati yang minimal pada pemberian $\mathrm{VCO}$ dosis $1 \mathrm{ml} / \mathrm{kgBB}$ dan $5 \mathrm{ml} / \mathrm{kgBB}$ menunjukkan adanya aktivitas antioksidan dari VCO tersebut. Dalam berbagai penelitia,n fenol terbukti memiliki efek antioksidan tehadap stres oksidatif; selain itu, vitamin $\mathrm{E}$ yang terkandung dalam VCO berperan dalam menghambat peroksidasi lipid oleh radikal bebas yang dibentuk dari persenyawaan NAPQI melalui mekanisme penangkapan radikal bebas, mempertahankan integritas membran sel dengan menghambat aktivitas nitrit oksida endotel. ${ }^{22}$ Namun semua mekanisme yang melibatkan efek hepatoprotektif VCO belum diketahui secara pasti dan membutuhkan penelitian-penelitian yang lebih lanjut. ${ }^{10}$

Kerusakan hati yang semakin berat pada kelompok P3 dengan gambaran degenerasi lemak yang difus walaupun diberikan dosis maksimal VCO menunjukkan hasil yang berbeda dengan penelitian Zakaria et al. ${ }^{10}$ Pada beberapa penelitian mengenai uji bahan hepatoprotektor dalam tubuh, pemberian dosis maksimal juga dapat memperberat kerusakan hati. ${ }^{23}$ Penyebab kerusakan hati pada P3 mungkin serupa dengan efek hepatoprotektor lainnya yang memperberat kerusakan hati bila diberikan dosis maksimal.

Pemberian VCO dan parasetamol yang dilakukan dalam waktu hampir bersamaan bisa saja menimbulkan berbagai efek maupun reaksi di dalam tubuh. Efek toksik suatu zat dapat dipengaruhi oleh zat kimia lain yang diberikan bersamaan. Efek toksik dapat berubah oleh karena berbagai hal seperti perubahan absorpsi, distribusi dan ekskresi zat kimia, peningkatan atau pengurangan biotransformasi, serta perubahan kepekaan reseptor pada organ sasaran. Kualitas bahan dan teknik pembuatan VCO juga memengaruhi hasil yang ditimbulkan. Perubahan histologik yang terjadi tergantung dosis, jenis, pengaruh zat atau penyakit lain, serta kerentanan. ${ }^{24}$

Pada penelitian ini, perubahan histologik umumnya yang menunjukkan adanya kerusakan jaringan hati tikus wistar berkurang pada kelompol P1 dan P2 walaupun belum mencapai gambaran normal. Hal ini dapat disebabkan oleh beberapa hal, antara lain: masih terdapat parasetamol sebagai faktor penyebab cedera hepatosit di dalam tubuh mencit, rentang waktu pemberian VCO mungkin kurang panjang, atau adanya kelainan hati yang tidak terdeteksi sebelum perlakuan. Diduga cedera mikroskopik hati wistar mungkin dapat berkurang atau pulih bila pemberian VCO dilakukan dengan rentang waktu lebih panjang, dosis yang sesuai, serta kontrol terhadap bias yang mungkin terjadi sebelum perlakuan.

\section{SIMPULAN}

Berdasarkan hasil penelitian dapat disimpulkan bahwa induksi parasetamol dosis toksik 2,5 $\mathrm{g} / \mathrm{kg}$ BB mengakibatkan perubahan histologik hati berupa degenerasi hidropik, degenerasi lemak, dan nekrosis hepatosit. Pemberian VCO dosis 1 $\mathrm{ml} / \mathrm{kgBB}$ dan $5 \mathrm{ml} / \mathrm{kgBB}$ dapat mengurangi degenerasi hidropik dan degenerasi lemak akibat parasetamol serta mampu meregenerasi hepatosit secara cepat dan lebih banyak. Pemberian VCO dosis maksimal $10 \mathrm{ml} / \mathrm{kgBB}$ memperbanyak cedera hepatosit dengan adanya degenerasi lemak yang difus. 


\section{UCAPAN TERIMA KASIH}

Ucapan terimakasih ditujukan kepada Prof. dr. Jimmy Posangi, MSc, PhD, SpFK dan dr. Poppy M. Lintong, SpPA(K) selaku penguji skripsi, staf Laboratorium Riset Terpadu dan Pusat Diagnostik Patologi Anatomi, serta semua pihak yang telah menumbuhkan ide dan gagasan pada penulis.

\section{DAFTAR PUSTAKA}

1. Fife B. The Healing Miracle of Coconut Oil (Third Edition). New York: Healthwise Colorado Springs; 2003.

2. Welasih T, Nurhapsari. Pembuatan Virgin Coconut Oil (VCO) dengan menggunakan metode sentrifugasi [Tesis]. Surabaya: Fakultas Teknologi Industri UPN Veteran Surabaya; 2009.

3. Direktorat Jenderal Pertanian. Luas Lahan dan Produksi Kelapa Tahun 2001-2004 di Indonesia. Jakarta: Direktorat Jenderal Pertanian; 2004.

4. Intahphuak $S$, Khonsung $P$, Panthong A. Anti-inflamatory, analgesic, and antipyretic activities of virgin coconut oil [abstract]. Pharm Biol. 2010;48(2):151-7.

5. Marina AM, Che Man BY, Nazimah AH, Amin I. Antioxidant capacity and phenolic acids of virgin coconut oil. International Journal of Food Science and Nutrition. 2009;60(2):114-23.

6. Enig MG. Coconut in suport of good health in 21 st century [homepage on the Internet]. 2001 [cited 2012 Sept 10]. Available from: http://www.bewellstay well.com/virgincoconutoil_facts.htm.

7. Nevin KG, Rajamohan T. Benefical effects of virgin coconut oil on lipid parameters and in vitro LDL oxidation. Clin Biochem. 2004;37(9):830-5.

8. Nevin KG, Rajamohan T. Wet and dry extraction of coconut oil: impact on lipid metabolic and antioxidant status in cholesterol coadministered rats. Can J Physiol Pharmacol. 2009; 87:610-6.

9. Nevin KG, Rajahoman T. Effect of topical aplication of virgin coconut oil on skin components and antioxidant status during dermal wound healing in young rats [abstract]. Skin Pharmacol Physiol. 2010; 23(6):290-7.

10. Zakaria ZA, Rofiee MS, Somchit MN,
Zuraini A, Sulaiman MR, Teh LK, et al. Hepatoprotective activity of dried and fermented processed virgin coconut oil. Hindawi Publishing Corporation. Available from: doi: $0.1155 / 2011 / 142739$.

11. Sam JV. Drugs that causes liver damage [homepage on the Internet]. Nodate [cited 2012 Oct 1]. Available from: URL: http://hepcnet.net/drugsandliver damage.html.

12. Larson AM, Polson J, Fontana RJ, Davern TJ, Lalani E, Hynan LA, et al. Acetaminophen-induced acute liver failure: results of a United States multicentre, prospective study. Hepatology (Baltimore, Md.). 2005;42(6):1364-72.

13. Anggraini R. Gambaran makroskopik dan mikroskopik hati dan ginjal mencit akibat pemberian plumbum asetat [Tesis]. Medan: Sekolah Pascasarjana Universitas Sumatera Utara; 2008.

14. Dart RC, Erdman AR, Olson KR, Christianson G, Manoguerra AS, Chyka PA, et al. Acetaminophen poisoning: an evidence-based consensus guideline for out of hospital management. Clinical Toxicology. 2006; 44(1):1-18.

15. Price A, Wilson M. Patofisiologi Konsep Klinis Proses Penyakit Volume 1. Alih bahasa: Anugerah P. Jakarta: EGC, 2003.

16. Maronpot RR, Boorman GA, Gaul BW, editors. Pathology of Mouse. Vienna IL: Cache River Press; 1999.

17. Mardiyyaningsih, Nurdini A, Ariyati E. Uji praklinis virgin coconut oil (VCO) terhadap kemampuan metabolisme hepatosit menggunakan uji SGPT pada mencit (Mus Musculus) [Tesis]. Tanjungpura: Fakultas Keguruan dan Ilmu Pendidikan Universitas Tanjungpura; 2007.

18. Mitchell RN, Cotran RS. Jejas, adaptasi dan kematian sel. In: Robbins SL, Kumar V, Cotran RS, editors. Buku Ajar Patologi I (Edisi 7). Jakarta: EGC, 2004.p.10-12.

19. Burt AD, Portmann BC, Ferrell LD. MacSween's Pathology of The liver (Fifth Edition). London: Churchill Livingstone Elsevier, 2007.

20. Michalopoulos GK. Liver Regeneration. J 
Cell Physiol. 2007; 213(2):286-300.

21. Wulandari T, Hartini M, Listyawati S. Pengaruh ekstrak daun sambiloto (Andrographis paniculata) terhadap struktur mikroanatomi hepar dan kadar glutamat piruvat transaminase serum mencit (mus muscullus) yang terpapar diazon. Bioteknologi. 2007;4(2):53-8.

22. Winarsi H. Antioksidan Alami dan Radikal Bebas. Yogyakarta: Kanisius, 2007.

23. Wulandari S. Pengaruh pemberian
Curcuma domestica terhadap gambaran histologi hepar mencit balb/c yang diberi parasetamol [Skripsi]. Semarang: Fakultas Kedokteran Universitas Diponegoro; 2008.

24. Liau KM, Lee YY, Chen CK, Rasool AH. An open label pilot study to assess the efficacy and safety of virgin coconut oil in reducing visceral adiposity. ISRN Pharmacol. 2011;2011:949686. 